\title{
Spatial and Mechanical Properties of Dilute DNA Monolayers on Gold Imaged by AFM
}

\author{
Donats Erts, ${ }^{*}, \dagger$ Boris Polyakov, ${ }^{\dagger}$ Håkan Olin, ${ }^{\dagger}$ and Eimer Tuite ${ }^{*, \S}$ \\ Institute of Chemical Physics, University of Latvia, Rainis Boulevard 19, LV-1586 Riga, Latvia, Physics and \\ Engineering Physics, Chalmers University of Technology, SE-412 96 Göteborg, Sweden, and Department of \\ Chemistry, Bedson Building, University of Newcastle, Newcastle upon Tyne NE1 7RU, U.K.
}

Received: May 23, 2002; In Final Form: January 3, 2003

\begin{abstract}
Spatially distributed DNA oligomer arrays on $\mathrm{Au}(111)$ surfaces were created by one-step co-assembly of mixed monolayers of alkanethiol-conjugated DNA and mercaptohexanol (MCH). Tapping-mode AFM was used to visualize the distribution of DNA molecules on the surface and to study the mechanical properties of individual molecules. The DNA coating density increased nonlinearly with increasing mole fraction of DNA oligomer to $\mathrm{MCH}$ in the coating solution. For imaging in air, where surfaces are coated with a thin layer of water, the interaction between the AFM tip and the different structures on the monolayer varies between attractive and repulsive depending on the tapping amplitude, set-point ratio, and tip shape. It was found that both duplex and single-stranded DNA molecules extend approximately vertically upward from the surface.
\end{abstract}

\section{Introduction}

Generating spatially addressable arrays of oligonucleotides on surfaces and characterizing their topographical and mechanical properties is important for many potential biotechnological and nanotechnological applications. DNA arrays are most familiar as tools for functional genomics in the form of diagnostic chips, where an optimized spatial distribution of DNA oligomers is required to ensure that recognition is not sterically compromised. In another context, DNA arrays find application as foundation templates for the construction of nanostructured materials via programmed self-assembly, ${ }^{1}$ where controlled spatial distribution is critical for structural integrity at the interface.

Densely coated DNA monolayers on gold surfaces have been described by several groups and are now becoming well understood..$^{2-8}$ The helix axis of $5^{\prime}$-alkanethiol-tethered duplexes was found to be oriented at $45^{\circ}$ with respect to the gold surface in close-packed monolayers, ${ }^{4}$ but the tilt angle can be controlled between $0^{\circ}$ and $90^{\circ}$ by the application of an appropriate potential..$^{4,8}$ However, $3^{\prime}$-linked duplexes ${ }^{7}$ and $5^{\prime}$-linked single strands ${ }^{8}$ both appear to favor lying flat on the surface. To overcome problems associated with strong gold-DNA interactions, mixed monolayers of thioalcohols and thioalkane-tethered DNA on gold surfaces have been created. Several methods for the preparation of DNA monolayers on gold have been reported in the literature, many based on procedures that are broadly applicable to biomolecule immobilization. However, these processes generally involve multiple steps. The most commonly used method, first described by Tarlov and Herne, is a DNAspecific method that involves first adsorbing DNA- $\left(\mathrm{CH}_{2}\right)_{n}-$ $\mathrm{SH}$ on gold and then displacing it with alkanethiol so that only the gold-sulfur linkage remains and the DNA molecules are distributed on the surface. ${ }^{9-16} \mathrm{~A}$ similar approach using an oligo(dA) spacer instead of an alkyl chain has also been reported. ${ }^{17}$

* To whom correspondence should be addressed. Eimer Tuite: e-mail e.m.tuite@ncl.ac.uk, tel. +44 191 2225523, fax +44 191 2226929. Donats Erts: e-mail erts@kfi.lu.lv, tel. +371 7323306, fax +371 7820113.

$\dagger$ University of Latvia.

$\doteqdot$ Chalmers University of Technology.

$\S$ University of Newcastle.
A related procedure involves reductive desorption of mercaptopropionic acid from a mixed monolayer and subsequent filling with mercaptohexyl-ssDNA. ${ }^{18}$ A second method involves deposition on gold of thioalkanes terminated with reactive groups. ${ }^{19-21}$ These surfaces can be activated to react with modified DNAs, producing a distribution of DNAs on the surface regulated either by steric and electrostatic interactions in the approach or by control of percentage activation. Another method involves the preparation of streptavidin modified monolayers to which biotinylated DNA molecules can be bound; ${ }^{22}$ the spatial characteristics in this case are thus controlled by those of streptavidin adsorption. An alternative single-step method for the formation of mixed DNA-thioalkane monolayers was described previously ${ }^{23}$ but has been rarely applied: ${ }^{24}$ coadsorption of hexadecanethiol-ssDNA and thiohexadecanol forms a mixed monolayer with a dilute surface density of immobilized DNA.

For DNA monolayers, the coating quality, density, and bond type have been variously studied using techniques that measure the bulk properties of the surface, e.g., neutron reflectivity, surface plasmon resonance, electrochemical assays, radioactive tagging, and ATR-IR spectroscopy. ${ }^{3,4,6,10,11,14}$ Although scanning probe techniques have been applied to densely packed goldmodified surfaces, ${ }^{4,7,8}$ few studies have been reported to date on dilute DNA-modified surfaces. ${ }^{18}$ Technical developments have allowed atomic force microscopy (AFM), including singlemolecule force spectroscopy, ${ }^{25-30}$ to be increasingly applied to investigate soft materials such as organic and biological molecules immobilized at surfaces, ${ }^{4,31-40}$ as well as compliant polymers. ${ }^{41-46}$ Tapping-mode (TM) is preferable to contact mode for soft samples such as biomolecules because of its smaller lateral forces. With TM-AFM, not only can the topography of surfaces be imaged, but phase images can also be obtained that show the surface as a function of the mechanical and adhesion properties of different adsorbed materials. The phase angle is the phase lag of the cantilever oscillation with respect to the drive oscillation. Hence, TM-AFM has been widely applied to study the mechanical properties of heterogeneous components at surfaces. ${ }^{33-39,41,43,47,48}$ 
TABLE 1: Sequences of Oligonucleotides Used in AFM Studies

\begin{tabular}{llc}
\hline oligo name & \multicolumn{1}{c}{ sequence } & length (linker + oligo) \\
\hline C6DNA10 & 5'-SH(CH$)_{6}$ GAG GTT GTG AGG CGC TGC CCC CAC CAT GAG-3' & $1+10 \mathrm{~nm}$ \\
DNA10* & 5'-CTC ATG GTG GGG GCA GCG CCT CAC AAC CTC-3' & $10 \mathrm{~nm}$ \\
C6DNA4 & 5'-SH(CH $\left.{ }_{6}\right)_{6}-$ GAG GTT GTG AGG-3' & $1+4 \mathrm{~nm}$ \\
DNA4* & 5'-CCT CAC AAC CTC-3' & $4 \mathrm{~nm}$
\end{tabular}

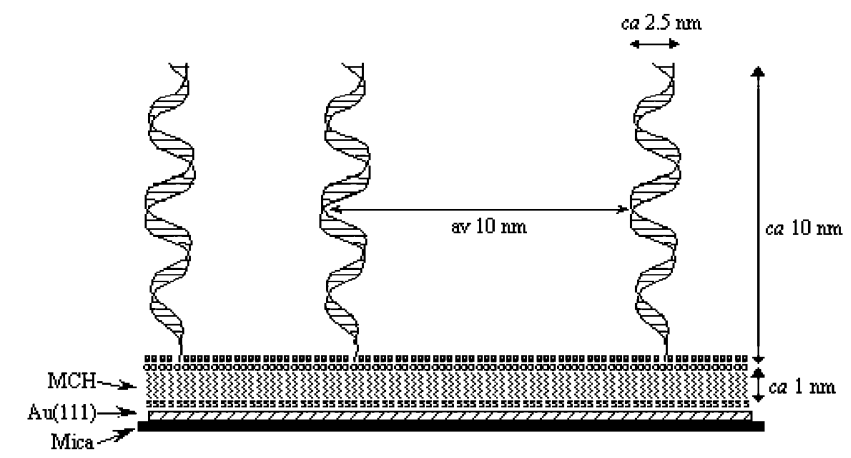

Figure 1. Schematic of the alkanethiol-dsDNA/mercaptohexanol coadsorbed mixed monolayer.

Our aim was to create spatially distributed DNA on a gold surface using a one-step preparation and to investigate the distribution and mechanical properties of individual molecules. In the present work, $5^{\prime}$-thioalkyl-oligonucleotides separated by thioalcohols were immobilized on $\mathrm{Au}(111)$ surfaces by a coadsorption procedure, similar to that described previously ${ }^{23}$ but using a shorter hexyl linker. ${ }^{49,50}$ SPR studies indicate that this produces a well-packed monolayer. ${ }^{49}$ TM-AFM was used to visualize individual DNA molecules in the mixed selfassembled monolayer (SAM) and to determine the distribution of DNA oligomers on the surface. To allow full interpretation of the height and phase images and to extract useful information about the samples under study, these images were recorded systematically as a function of different tapping-mode parameters as well as tip shape.

\section{Experimental Section}

2.1. Materials. DNA oligonucleotides synthesized with a $5^{\prime}-\left(\mathrm{CH}_{2}\right)_{6} \mathrm{SH}$ terminal substituent, purified and desalted by FPLC, were obtained as lyophilized samples from Eurogentec that were resuspended in $5 \mathrm{mM}$ phosphate buffer $(\mathrm{pH}$ 6.9) for experiments. The solutions were kept at $-20{ }^{\circ} \mathrm{C}$ for long-term storage or at $4{ }^{\circ} \mathrm{C}$ under nitrogen when in use; under such conditions, they gave reproducible surface modifications for weeks. Mercaptohexanol was from Fluka (purum, $\geq 97 \%$ ) and was stored under nitrogen. $\mathrm{MQ}-\mathrm{H}_{2} \mathrm{O}$ was used for all solution preparations, and all salts and solvents were analytical grade. $\mathrm{Au}(\mathrm{III})$-coated mica was obtained from Structure Probe Inc. Supplies and used as received.

The investigated samples were double-stranded DNA oligomers that were $4 \mathrm{~nm}$ (12-mer, C6DNA4 and its complement DNA4*) and $10 \mathrm{~nm}$ (30-mer, C6DNA10 and its complement DNA10*) long. The sequences used are shown in Table 1 and represent a mutation hotspot region in the p53 gene.

2.2. DNA Immobilization. The surface modification shown schematically in Figure 1 was achieved by coadsorbing thioalkylated DNA and mercaptohexanol (MCH) onto $\mathrm{Au}(111)$ surfaces deposited on mica. Both the oligonucleotides used are shorter than the persistence length of double-stranded DNA (50 $\mathrm{nm}^{52}$ ) and are thus expected to behave as rigid rods. The persistence length of ssDNA is $1-7 \mathrm{~nm}$, depending on ionic strength $\left(\sim 7 \mathrm{~nm}\right.$ at $1 \mathrm{mM}$ TEA and $\sim 1 \mathrm{~nm}$ at $100 \mathrm{mM}$ TEA) ${ }^{53}$
Oligonucleotide lengths are $3.4 \AA$ /base pair for $\mathrm{dsDNA}^{52}$ and $4.3 \AA$ Abase for ssDNA. ${ }^{53}$ The thiolated oligonucleotides were hybridized with their perfect complements (with 20-50\% excess of nonthiolated complement to ensure complete hybridization) in $5 \mathrm{mM}$ phosphate ( $\mathrm{pH}$ 6.9) buffer by heating to $80{ }^{\circ} \mathrm{C}$ for $30 \mathrm{~min}$ and then cooling slowly to room temperature. Thiolated duplexes and $\mathrm{MCH}$ (diluted in ethanol) were mixed in various mole fractions to obtain a final total thiol concentration of $10 \mu \mathrm{M}$ in a buffer of $5 \mathrm{mM}$ phosphate containing $<1 \%$ ethanol. Small pieces (ca. $5 \mathrm{~mm} \times 7 \mathrm{~mm}$ ) of gold-coated mica were immersed in this solution for $1-2 \mathrm{~h}$, a period previously estimated from surface plasmon resonance (SPR) experiments as appropriate for complete monolayer formation in these systems. ${ }^{51}$ The surfaces were then extensively washed with $\mathrm{MQ}-\mathrm{H}_{2} \mathrm{O}$ and $5 \mathrm{mM}$ phosphate buffer to remove unbound material, particularly unhybridized complementary DNA, and were stored in this buffer prior to removal for scanning; monolayers stored in this way were judged to be stable for up to 2 weeks. Single-stranded 4-nm-long DNA oligomers were investigated for comparison, and surfaces were prepared identically except that the hybridization step was eliminated.

2.3. AFM Measurements. The samples were not vigorously dried before imaging but were allowed to evaporate under ambient conditions until no surface water was apparent to the naked eye; it is expected that the samples will retain a thin layer of water. AFM measurements were carried out in air with humidity maintained at $45-60 \%$, which should be sufficient to ensure that the DNA remains hybridized, although its preferred conformation under these conditions could be A-form rather than the B-form adopted in solution.

Imaging and phase interaction data were collected using a Nanoscope III Dimension 3000 AFM (Digital Instruments, Santa Barbara, CA) operating in tapping mode. Silicon tips with a resonance frequency of $280-330 \mathrm{kHz}$ and a force constant of $40 \mathrm{~N} / \mathrm{m}$ were used. Images were collected at the fundamental resonance frequency of $\mathrm{Si}$ cantilevers. The phase shift was measured as a function of the set-point ratio, $r_{\mathrm{sp}}=A_{0} / A_{\mathrm{sp}}$, where $A_{\mathrm{sp}}$ is the set-point amplitude (also known as the drive amplitude), ${ }^{34,39,41,47}$ for several $A_{0}$ values, where $A_{0}$ is the cantilever amplitude of free oscillations. It has been shown that the tip-sample interaction in tapping mode is sensitive to $A_{0}$, $r_{\mathrm{sp}}$, and the tip shape. ${ }^{47}$ Various models of tip-sample interaction that can be applied to different systems have been described previously. ${ }^{35,41,54-64}$ Basic measurements were made at $A_{0}=$ $45 \mathrm{~nm}$. For tip-sample interaction analysis, the samples were measured at amplitudes of 12, 25, 45, 70, and $100 \mathrm{~nm}$. The use of lower amplitudes produced indistinct images. In the experiments, both sharp and blunt tips were used. Blunt tips were produced by prolonged $(3-4 \mathrm{~h})$ scanning of sharp tips over hard surfaces containing sharp steps.

A home-built AFM was used for relative surface stiffness measurements. Force vs displacement curves were obtained with tip approach speeds between 60 and $2900 \mathrm{~nm} / \mathrm{s}$. The AFM tips were of standard silicon nitride. The force constant of the cantilever was measured using calibrated cantilevers ${ }^{65}$ and was found to be around $0.10 \mathrm{~N} / \mathrm{m}$. 

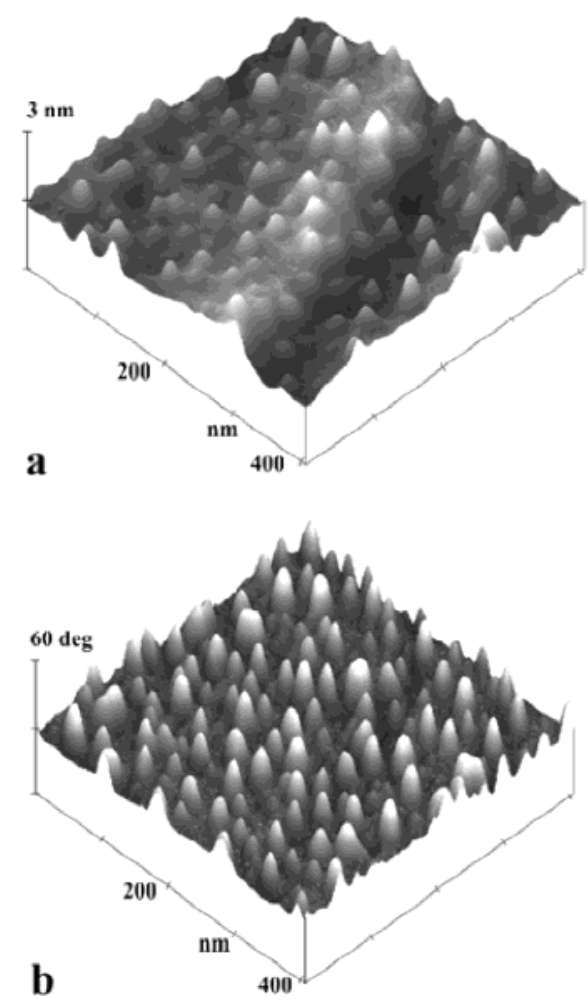

Figure 2. TM-AFM images of the same area of $\mathrm{Au}(111)$ coated with a mixed monolayer of C6DNA10/DNA10* (10\% mole fraction in solution) and mercaptohexanol: (a) height, (b) phase response. $A_{0}=$ $45 \mathrm{~nm}, r_{\mathrm{sp}}=0.6$

\section{Results and Discussion}

Images of surfaces coated with DNA recorded either in height or phase mode exhibited contrast variations (Figure 2) that depended on experimental conditions: $A_{0}, r_{\mathrm{sp}}$, and the tip shape.

For the C6DNA10/DNA10* duplex, 0.5-4-nm-high protrusions were observed at $r_{\mathrm{sp}}$ values below $\sim 0.85$. Because similar structures were not observed on surfaces treated only with mercaptoethanol, they were assigned as oligonucleotides extending upward from the surface. However, the height of DNA in these images was lower than that expected for a rigid extended DNA duplex oriented normal to the surface $(\sim 10 \mathrm{~nm}$ for a B-form conformation). Additionally, the diameter of the structures $(\sim 20 \mathrm{~nm})$ was larger than that expected for a single DNA molecule protruding from the surface $\left(\sim 2.5 \mathrm{~nm}^{52}\right)$. This might be a result of real tip shape convolution over the structure, but other factors including thickness of the adsorbed water layer and the flexibility of the DNA at the attachment point might also influence the apparent diameter, as discussed later. As a rule, the apparent height of the DNA decreased with lower setpoint ratios $\left(r_{\mathrm{sp}}=A_{0} / A_{\mathrm{sp}}\right)$, i.e. with increasing tip-sample interaction force. Two or three types of structures with different heights were usually observed. Differences in the height of various structures were more pronounced when surface coatings were denser and when sharper tips were used. This might be due to differences in the tip interaction with individual DNA oligomers compared with groups of several oligomers adsorbed in close proximity.

DNA structures were better resolved in the phase images (Figure 2b). The phase response originates from local differences in tip-surface interactions, arising as the tip probes chemically different components. The interaction is likely different for $\mathrm{MCH}$ (presenting $\mathrm{OH}$ headgroups) and DNA oligomers (presenting ionized phosphate groups), and additionally, it might depend

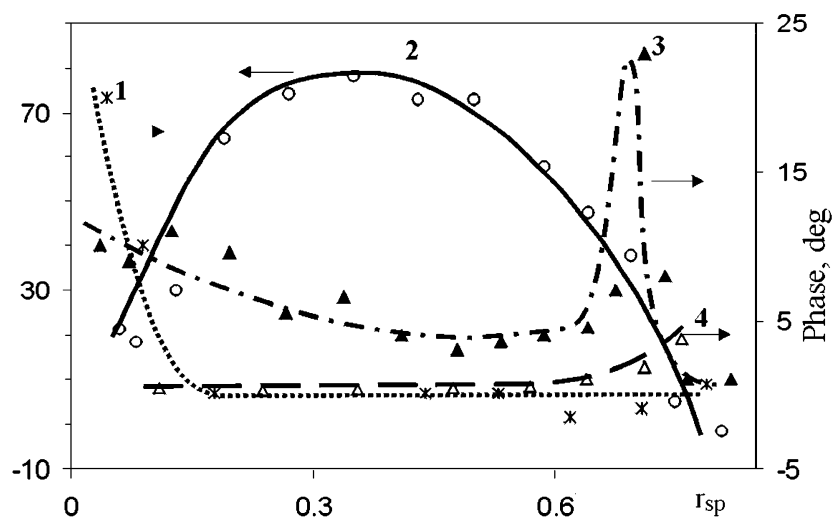

Figure 3. TM-AFM phase response for DNA oligomers in a mixed monolayer of C6DNA10/DNA10* (1\% mole fraction in solution) and mercaptohexanol as a function of set-point ratio at various tip oscillation amplitudes $\left(A_{0}\right)$ : (1) 25, (2) 45, (3) 65, and (4) $100 \mathrm{~nm}$. A blunt tip was used in the experiment.

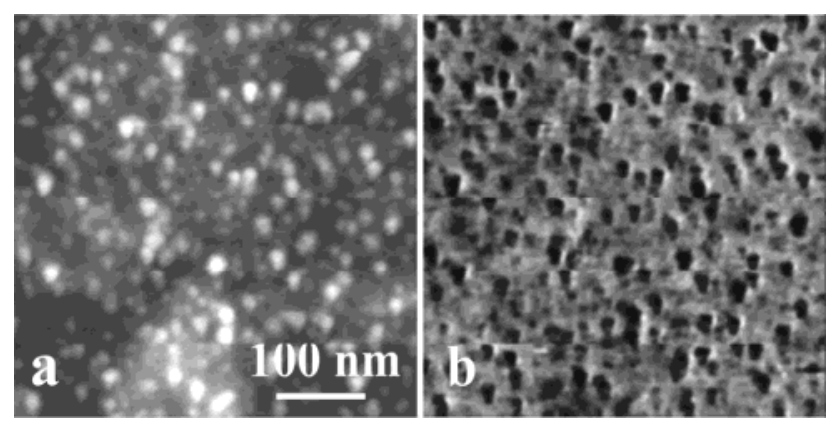

Figure 4. Tapping-mode AFM images of the same area of $\mathrm{Au}(111)$ coated with a mixed monolayer of C6DNA4/DNA4* $(1 \%$ mole fraction in solution) and mercaptohexanol: (a) height, (b) phase response. $A_{0}$ $=45 \mathrm{~nm}, r_{\mathrm{sp}}=0.8$. Gray scales: (a) $7 \mathrm{~nm}$ and (b) $15^{\circ}$.

on differential absorption of water on MCH and DNA. The tip interaction with water is typically attractive owing to capillary forces, and the effect of water on tapping-mode images has been described in the case of Nafion membranes, for example. ${ }^{39}$ Thiols with a $-\mathrm{COOH}$ headgroup show intrinsic attractive behavior, ${ }^{33}$ and by analogy, there is likely to be an attractive interaction between the AFM tip and $\mathrm{MCH}$. The value of the observed phase shift depended on the scanning parameters and the tip shape. Often, the response was less pronounced if sharp tips were used, perhaps as a result of a decreased contact area.

Figure 3 shows how the set-point ratio affected the phase shift for the DNA oligomer structures at different cantilever free amplitudes $A_{0}$ when a blunt tip was used. In most cases, the phase shift was more positive for the DNA structures than for areas coated by $\mathrm{MCH}$. This suggests that the effect of the indentation force is felt more strongly by the stiff DNA duplex. The tip interaction exhibited attractive behavior on the areas occupied by the $\mathrm{MCH}$ and therefore showed a negative phase shift or was close to 0 in most cases. For each $A_{0}$, the phase response on DNA structures goes through a maximum at different set-point ratios (Figure 3).

At small $A_{0}$ (e.g., $45 \mathrm{~nm}, 25 \mathrm{~nm}$ and also $12 \mathrm{~nm}$ for which data are not shown in Figure 3) and large $r_{\mathrm{sp}}$ (low applied force), the phase shift on DNA was close to 0 (Figure 3) or even negative (Figure 4). The negative phase response for the DNA structure might be explained by an attractive interaction between the tip and the water layer adsorbed on DNA. It is possible that the image is due to the tip interacting only with the adsorbed water layer and not encountering directly the DNA oligomer. 

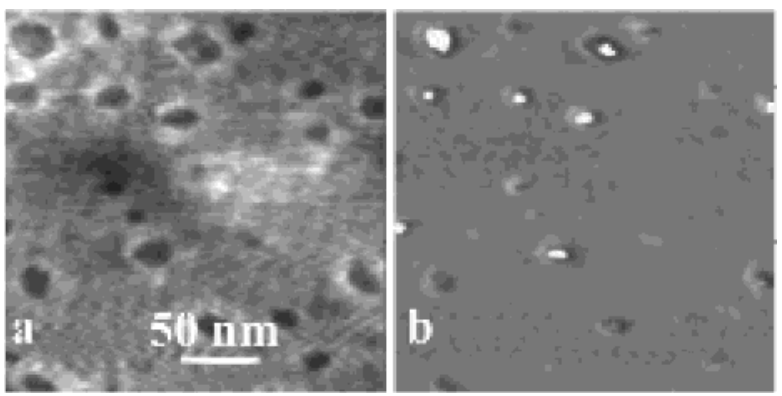

Figure 5. TM-AFM images of the same area of $\mathrm{Au}(111)$ coated with a mixed monolayer of C6DNA4 ( $0.1 \%$ mole fraction in solution) and mercaptohexanol. (a) height, (b) phase response. Gray scales: (a) 8 $\mathrm{nm}$ and (b) $60^{\circ} . A_{0}=12 \mathrm{~nm}, r_{\mathrm{sp}}=0.4$.

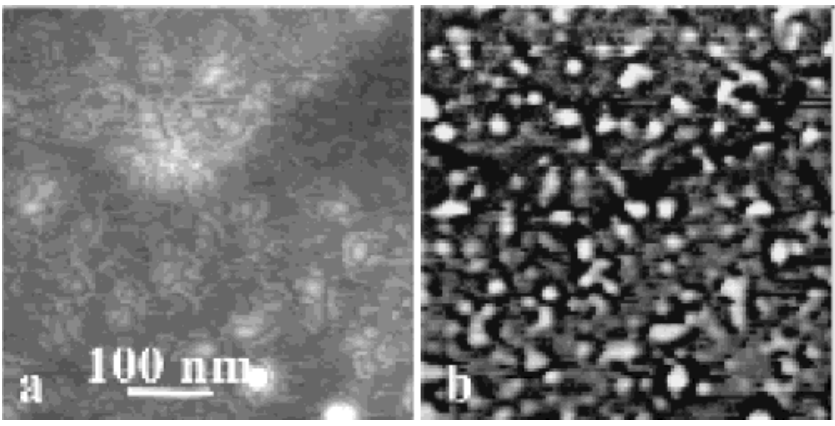

Figure 6. Instabilities observed in the TM-AFM images of the same area of $\mathrm{Au}(111)$ coated with a mixed monolayer of C6DNA10/DNA10* (1\% mole fraction in solution) and mercaptohexanol: a) height, (b) phase response. Gray scales: (a) $5 \mathrm{~nm}$ and (b) $90^{\circ} . A_{0}=45 \mathrm{~nm}, r_{\mathrm{sp}}$ $=0.5$.

Where the phase response on DNA was negative, the values of $r_{\text {sp }}$ decreased in the order $10 \mathrm{~nm}$ dsDNA $<4 \mathrm{~nm}$ dsDNA $<4$ $\mathrm{nm}$ ssDNA. This might be caused by differences in the thicknesses of the adsorbed water layer on different DNA structures, in addition to different flexibilities of the constructs.

For a very narrow range of scanning parameters $\left(A_{0}=12 \mathrm{~nm}\right.$, $\left.r_{\mathrm{sp}}=0.2-0.4\right)$, images were obtained in which even the DNA height was negative, and this effect was more pronounced for single-stranded DNA (Figure 5).

This might be a result of much larger-amplitude damping in the $\mathrm{MCH}$ regions compared to the DNA structures with certain tapping parameters. Similar reverse height effects have been observed previously ${ }^{33,35}$ for Au surfaces coated with SAMs.

As well as cases of clearly negative and positive values of height and phase angles, at certain scanning parameters, instabilities in both phase and height images were observed. For example, for the $10 \mathrm{~nm}$ DNA duplex at $A_{0}=45 \mathrm{~nm}$, instabilities were observed within an $r_{\mathrm{sp}}$ interval of $0.3-0.5$ (Figure 6). Similar contrast flipping has been reported previously ${ }^{39,60}$ and explained as a bistable behavior of the system due to sudden transitions from a noncontact region to an intermittent contact region at certain scanning parameters. ${ }^{60}$ Instabilities might occur not only because of the coexistence of attractive and repulsive forces but also because of the influence of capillary effects caused by thin liquid layers on the sample.

The images shown so far are for surfaces prepared with low mole ratios of DNA in the coating solution. For such surface modification, the DNA structures are well-resolved. However, when the mole fraction of DNA is increased to produce denser coatings, the resolution is severely diminished. Rather than resolved narrow protrusions appearing in the phase response and height images, the topography starts to show broad undulations due to the collective interaction of several DNA

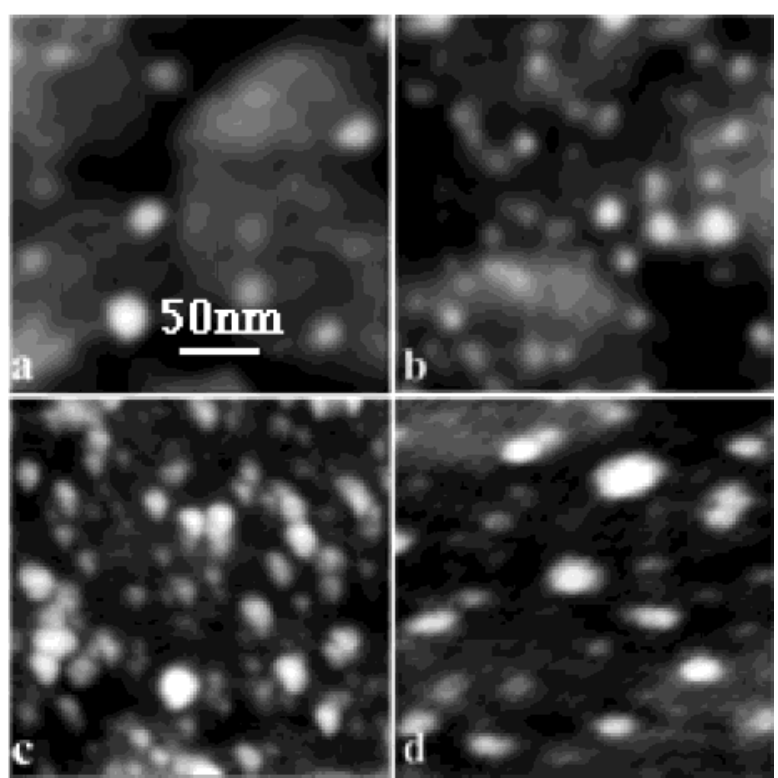

Figure 7. TM-AFM surface morphology images of mixed monolayers of C6DNA10/DNA10* and mercaptohexanol adsorbed on $\mathrm{Au}(111)$ from coating solutions containing different mole fractions of DNA. (a) $0.1 \%$, (b) $1 \%$, (c) $50 \%$, (d) $1 \%$ ss-C6DNA10. Gray scale: $10 \mathrm{~nm}$ in all images.

oligomers with the tip. However, at certain $r_{\mathrm{sp}}$ and $A_{0}$ values, it was possible to resolve narrow features within these broad structures in the phase images and to measure the distance between individual DNA oligomers inside a group. For $50 \%$ mole fraction in a solution of 10-nm DNA, the distance between adjacent adsorbed oligonucleotides was estimated as $6-8 \mathrm{~nm}$, which was larger than the Debye radius.

The density of DNA molecules adsorbed on the surfaces was estimated from the AFM images. Figure 7 shows height images of DNA mixed monolayers formed from solutions containing different mole fractions of thiol-modified DNA with respect to $\mathrm{MCH}$. The DNA density was found to increase nonlinearly with DNA mole fraction in the solution, as was also found when similarly modified surfaces were characterized using spectroscopy and electrochemistry. ${ }^{49} \mathrm{We}$ found that the double-stranded DNA density was $2-3 \times 10^{10}, 1 \times 10^{11}$, and $2-3 \times 10^{11}$ molecules $/ \mathrm{cm}^{2}$ for monolayers formed from solutions containing DNA at mole fractions of $0.1,1$, and $50 \%$, respectively. For the $50 \%$ mole fraction, the determined DNA density on the surface is a lowest estimate because it was problematic to resolve individual DNA molecules clustered in close-packed groups. The density of single-stranded DNA oligomers on the surface was consistently somewhat lower than that for double-stranded oligomers at the same mole fraction (e.g. $4-6 \times 10^{10}$ molecules/ $\mathrm{cm}^{2}$ with $1 \%$ mole fraction in solution). The maximum oligonucleotide density in our spatially distributed DNA monolayers was more than an order of magnitude lower than that in densely packed monolayers of DNA oligomers formed without a diluant alkanethiol. The coverage of HS-ssDNA in densely packed monolayers was found to be $(3.5-23) \times 10^{12}$ molecules/ $\mathrm{cm}^{2}$. 3,6 The DNA density in mixed DNA oligomers-alkanethiol monolayers was reported to be $(1-9) \times 10^{12}$ molecules/ $\mathrm{cm}^{2}{ }^{2,10-12,14}$ It is likely that the surface coverage using $50 \%$ DNA in the coating solution approaches densities of this magnitude, although we were unable to estimate it exactly. The densities we have determined might differ from those measured by other groups who have used methods that measure the bulk properties, because we have measured the DNA distribution locally rather than on the entire surface. Nonetheless, our measurements in different areas of the same surface generally 
gave similar results, although occasionally areas were found where no structures were well-resolved.

The AFM images provide a good picture of how the DNA molecules are distributed within the mixed monolayer, but under the conditions used, the shapes of the structures are not as anticipated for oligonucleotides, as they appear shorter and fatter than B-form DNA molecules. Even radical conformational changes could not produce the observed structures, and in any case, because of the high relative humidity used in the experiments, we expect that the B-form is indeed adopted. A relevant question then is whether the DNA molecules extend vertically upward in these monolayers, are tilted relative to the surface as in close-packed coatings, ${ }^{4}$ or lie flat along the top of the surrounding $\mathrm{MCH}$ layer. Because it is not the oligonucleotide molecules themselves that self-assemble to form the monolayer in our case, they are unlikely to have a fixed angle tilt to the surface because they are generally far from close-packed. Furthermore, the low ionic strength ( $5 \mathrm{mM}$ phosphate buffer) used in our experiments should help to prevent adjacent molecules from approaching each other closely. The oligonucleotides probably do extend upward from the monolayer; because they are much shorter than the persistence length of DNA, they will behave as rigid rods but will not necessarily orient normal to the surface. Because of free rotation about the bond that links the oligonucleotide to the thiohexane linker, the DNA molecules are likely to have a distribution of configurations about the vertical axis. However, the thiohexyl linker is attached directly to the oxygen of the 5'-phosphate, which would make it difficult for the DNA molecules to approach close to the surrounding $\mathrm{MCH}$ surface without distorting the monolayer. We have observed that attaching the DNA via a 3'-( $\left.\mathrm{CH}_{2}\right)_{3}$-linker coadsorbed with $\mathrm{MCH}$ produced an imperfect monolayer. ${ }^{49}$ Furthermore, there is unlikely to be any special attraction between the DNA molecules and the alcohol groups at the surface to drive such an interaction.

There are a number of possible factors that could be responsible for the apparent lowering of the DNA height during scanning. The lateral force acting on the DNA oligomer as the tip approaches the sharp structures during scanning might be sufficient to push the DNA oligomers toward the surface and possibly cause the oligonucleotides to bend. Considerable force is applied in these experiments, and it has been shown previously that, in tapping mode, the AFM tip can deeply indent the surface during scanning of compliant samples by up to several tens of nanometers. ${ }^{45,46}$ Random-sequence single-stranded oligonucleotides would be more easily bent than duplexes because most of the mechanical rigidity of DNA comes from the stacking of the bases. ${ }^{66}$ Therefore, the persistence length of duplex DNA $\left(\sim 50 \mathrm{~nm}^{52}\right)$ is much longer than that of single-stranded DNA $\left(\sim 1-7 \mathrm{~nm}^{53}\right)$. However, even excluding bending of DNA, the lateral forces might knock the DNA molecules further from normal than usual, even to the extent that they might lie flat on top of the surrounding $\mathrm{MCH}$ layer. Averaged over all space, the DNA molecules would then look shorter and broader than predicted, and this would provide a reasonable explanation for the observed structures. However, it does not explain all our observations because the single-stranded 4-nm oligonucleotides tend to show structures in both height and phase images with a diameter (15-20 nm) larger than could be caused by them lying flat. It is likely, as mentioned earlier, that larger-than-predicted diameters of the protrusions are caused by real tip shape convolution over the structure. Another factor that could undoubtedly influence the observations is the difference in the thicknesses of the water layers adsorbed on the DNA single
TABLE 2: Surface Stiffness $^{a}$ of Mixed C6DNA10/ DNA10*-MCH and Pure MCH Self-Assembled Monolayers as a Function of Approach Speed of the AFM Tip ${ }^{b}$

\begin{tabular}{cccc}
\hline speed $(\mathrm{nm} / \mathrm{s})$ & $50 \%$ DNA & $1 \%$ DNA & MCH \\
\hline 2900 & 0.75 & 0.70 & 0.70 \\
1200 & 0.63 & 0.56 & 0.67 \\
60 & 0.55 & 0.44 & 0.62
\end{tabular}

${ }^{a}$ Relative to cantilever stiffness. ${ }^{b}$ Cantilever force constant was 0.1

strands, duplexes, and MCH surfaces. The lower height of DNA observed in the AFM images might be caused by the presence of a thicker water layer on the $\mathrm{MCH}$ monolayer compared to that coating the DNA. This would lead to an apparently smaller difference in height between the two structures because the tip senses the water layer. One additional potential cause of apparently reduced oligonucleotide height in TM-AFM images could be that the contact time for the tip exceeded the DNA oligomer mechanical relaxation time, thereby causing mechanical distortion.

The viscoelastic responses of the mixed DNA-MCH and pure $\mathrm{MCH}$ monolayers were analyzed from relative surface stiffness (calculated as the relation of cantilever displacement to sample displacement) measurements using soft cantilevers (see Table 2).

For the different surfaces, the dependence of the relative surface stiffness on approach speed was evaluated: for soft surfaces, the relative surface stiffness was expected to drop with decreasing approach speed. For both pure MCH SAMs and mixed C6DNA10/DNA10*-MCH SAMs, the surface stiffness decreased with lower tip approach speed (Table 2), which was evidence for a viscoelastic response of $\mathrm{MCH}$ and DNA molecules. The time that the tip spends in contact with the monolayers (5-10 and 50-100 ms for approach speeds of 2900 and $60 \mathrm{~m} / \mathrm{s}$, respectively) might be comparable to the mechanical relaxation time of monolayer components. For example, the mechanical relaxation time for $n$-hexadecylthiol was found to be 80 ms. ${ }^{67}$ Therefore, viscoelastic elements might have insufficient time to respond during fast tip movement in the monolayer. The decrease in stiffness with lower approach speed was greater for mixed monolayers containing DNA oligomers than for pure MCH monolayers (Table 2). This fact suggests that the mechanical relaxation time for oligonucleotides is shorter than that for a close-packed MCH monolayer. The changes in relative stiffness depend on the DNA density on the surface. Decreasing the DNA density at the surface, so that fewer DNA molecules are involved in the contact, caused the effective stiffness to drop with decreasing approach speed (see Table 2). Hence, it appears that oligonucleotides adsorbed in isolation are more free to respond to external mechanical stimulus than those that are adsorbed close to each other, presumably because of the removal of both spatial and electrostatic constraints in the former. Therefore, mechanical responses to the tip during tapping as well as differential water absorption on different components of the mixed monolayer might be responsible for the nonstandard DNA structures observed in conventional TM-AFM images.

To assign more convincingly the structures on the surface as DNA oligonucleotides, we applied TM-AFM in lift mode to determine whether DNA oligonucleotides do extend vertically upward in low-density coatings. Typical images were obtained when measuring the phase response of a mixed monolayer of C6DNA10/DNA10* and MCH (Figure 8). Repeated scans were then recorded at increasing distances from the surface and 

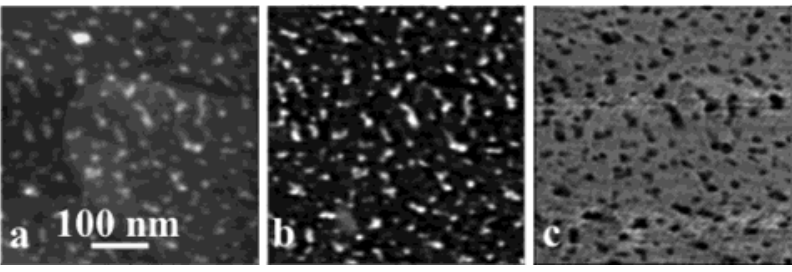

Figure 8. TM-AFM images in lift mode of $\mathrm{Au}(111)$ coated with mixed monolayers of C6DNA10/DNA10* (1\% mole fraction in solution) and mercaptohexanol. (a) height response, no lift; (b) phase response, no lift; (c) phase response, lift height $12 \mathrm{~nm}$. Gray scales: (a) $10 \mathrm{~nm}$, (b) $20^{\circ}$, and (c) $15^{\circ} \cdot A_{0}=45 \mathrm{~nm}$ and $r_{\mathrm{sp}}=0.66$

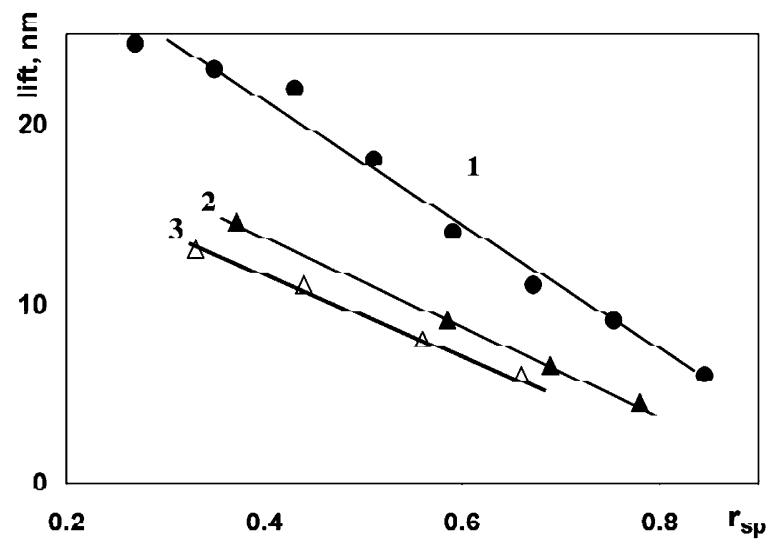

Figure 9. The maximum height at which structures were still observed in lift mode as a function of set-point ratio for $A_{0}=45 \mathrm{~nm}$. (1) C6DNA10/DNA10*, (2) C6DNA4/DNA4*, (3) C6DNA4.

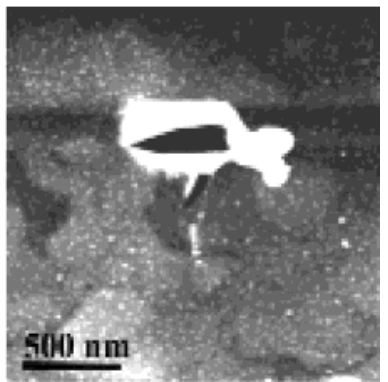

Figure 10. TM-AFM height image a mixed monolayer of C6DNA10/ DNA10* $(0.1 \%$ mole fraction in solution) and mercaptohexanol. The area in which the monolayer is destroyed was scanned with a high applied load $\left(r_{\mathrm{sp}}=0.1, A_{0}=45 \mathrm{~nm}\right)$. Gray scale: $20 \mathrm{~nm}$.

revealed structures with identical spatial arrangements (Figure $8 \mathrm{c}$ for a 12-nm displacement).

The phase response with increasing displacement from the surface became negative in most cases. The maximum lift height at which the phase response was still observed depended on $r_{\mathrm{sp}}$ and the length of DNA (Figure 9). This lift height was directly related to the length of the DNA oligomers at low applied loads (high $r_{\mathrm{sp}}$ ). At $r_{\mathrm{sp}}=0.8$, the lift heights were around 5 and $8 \mathrm{~nm}$ for 4- and 10-nm-long DNA oligomers, respectively. This finding serves as evidence that DNA oligomers do not lie on the surface but are extended vertically upward from the monolayer. The lift height at which the structures were observed was almost the same for the $4 \mathrm{~nm}$ single- and double-stranded DNA oligomers (Figure 9), which implies that single-stranded DNA also tends to extend orthogonally to the surface in mixed monolayers. The maximum lift height increased proportionally with decreasing $r_{\mathrm{sp}}$ (increasing applied load) (Figure 9). A decrease of $r_{\mathrm{sp}}$ from 0.8 to 0.4 caused increases in lift height to 14 and $21 \mathrm{~nm}$ for 4- and 10-nm-long DNA, respectively. The increases in lift height were 10-11 nm longer than the length of the DNA oligomers. Probably at low loads (high $r_{\mathrm{sp}}$ ), the tip scans the top of the structures without strongly interacting with the surface. At higher applied loads, the tip likely penetrates the DNA layer, and at $r_{\mathrm{sp}}$ below 0.3, the DNA molecules might be completely compressed. At very high loads $\left(r_{\mathrm{sp}}=0.1\right)$, the monolayer structure becomes compromised by the force of the tip interaction and was found to be destroyed when sharp tips were used (e.g. Figure 10).

\section{Conclusion}

Spatially distributed DNA oligomer monolayers have been created on $\mathrm{Au}(111)$ and investigated by TM-AFM in ambient conditions with respect to the set-point ratio, oscillation amplitude, and tip shape. The surface density of DNA molecules increased nonlinearly as the oligonucleotide concentration was raised in the coating solution. It was found that interactions between the tip and either mixed DNA- MCH monolayers or pure $\mathrm{MCH}$ monolayers can be attractive or repulsive depending on the scanning parameters employed. Observed oligonucleotide structures were shorter and broader than expected for B-form DNA. Force curve measurements showed that the viscoelastic response of DNA should be taken into account in the analysis and that mechanical reponse to the tip during tapping as well as interactions with the thin adsorbed water layer might be responsible. It was shown that lift mode can be applied to probe the real height of the extended DNA structures with respect to the surface.

Acknowledgment. We thank Prof. Wolfgang Knoll (MaxPlanck-Institut für Polymerforschung, Mainz, Germany) for the introduction to self-assembled DNA monolayers. We thank S. Kubatkin for helpful discussions. This work was financially supported by the Council of Science of Latvia, the University of Latvia (Grant Nr. 19), the Swedish Institute, and the University of Newcastle.

\section{References and Notes}

(1) Storhoff, J. J.; Mirkin, C. A. Chem. Rev. 1999, 99, 1849-1862. 84

(2) Maeda, M.; Mitsuhashihi, Y.; Takagi, M. Anal. Sci. 1992, 8, 83-

(3) Kelly, S. O.; Barton, J. K. Angew. Chem., Int. Ed. 1999, 38, 941945.

(4) Kelly, S. O.; Barton, J. K.; Jackson, N. M.; McPherson, L. D.; Potter, A. B.; Spain, E. M.; Allen, M. J.; Hill, M. G. Langmuir 1998, 14, 6781-6784.

(5) Kelly, S. O.; Jackson, N. M.; Hill, M. G.; Barton, J. K. Bioconjugate Chem. 1997, 8, 31-37.

(6) Hartwich, G.; Caruana, D. J.; de Lumley-Woodyear, T.; Wu, Y.; Campbell, C. N.; Heller, A. J. Am. Chem. Soc. 1999, 121, 10803-10812.

(7) Sam, M.; Boon, E. M.; Barton, J. K.; Hill, M. G.; Spain, E. M. Langmuir 2001, 17, 5727-2730.

(8) Zhang, Z.-L.; Pang, D.-W., Zhang, R.-Y.; Yan, J.-W.; Mao, B.W.; Qi, Y.-P. Bioconjugate Chem. 2002, 13, 104-109. 3402 .

(9) Herne, T. M.; Tarlov, M. J. J. Am. Chem. Soc. 1997, 119, 3401-

(10) Peterlinz, K. A.; Georgiadis, R. M. J. Am. Chem. Soc. 1997, 119, $3401-3402$

(11) Levicky, R.; Herne, T. M.; Tarlov, M. J.; Satija, S. K. J. Am. Chem. Soc. 1998, 120, 9787-9792.

(12) Steel, A. B.; Herne, T. M.; Tarlov, M. J. Anal. Chem. 1998, 70, $4670-4677$.

(13) Steel, A. B.; Herne, T. M.; Tarlov, M. J. Bioconjugate Chem. 1999 $10,419-423$.

(14) Georgiadis, R.; Peterlinz, K. P.; Peterson, A. W. J. Am. Chem. Soc. 2000, 122, 3166-3173.

(15) Peterson, A. W.; Heaton, R. J.; Georgiadis, R. J. Am. Chem. Soc. 2000, 122, 7837-7838

(16) Steel, A. T.; Levicky, R. L.; Herne, T. M.; Tarlov, M. J. Biophys. J. 2000, 79, 975-981. 
(17) Demers, L. M.; Mirkin, C. A.; Mucic, R. C.; Reynolds, R. A., III; Letsinger, R. L.; Elghanian, R.; Viswanagham, G. Anal. Chem. 2000, 72 5535-5541 7644 .

(18) Satjapipat, M.; Sanedrin, R.; Zhou, F. Langmuir 2001, 17, 7637-

(19) Brockman, J. M.; Frutos, A. G.; Corn, R. M. J. Am. Chem. Soc. 1999, 121, 8044-8051.

(20) He, L.; Musick, M. D.; Nicewarner, S. R.; Salinas, F. G.; Benkovic, S. J.; Natan, M. J.; Keating, C. D. J. Am. Chem. Soc. 2000, 122, $9071-$ 9077.

(21) Boncheva, M.; Scheibler, L.; Lincoln, P.; Vogel, H.; Åkerman, B. Langmuir 1999, 15, 4317-4320.

(22) Liebermann, T.; Knoll, W.; Sluka, P.; Herrmann, R. Colloids Surf. 2000, 169, 337-350.

(23) Noy, A.; Vezenov, D. V.; Kayyem, J. F.; Meade, T. J.; Lieber, C. M. Chem. Biol. 1997, 4, 519-527.

(24) Pope, L. H.; Allen, S.; Davies, M. C.; Roberts, C. J.; Tendler, S. J. B.; Williams, P. M. Langmuir 2001, 17, 8300-8304.

(25) Fritz, J.; Anselmetti, D.; Jarchow, J.; Fernàndez-Busquets, X. J. Struct. Biol. 1997, 119, 165-171.

(26) Ludwig, M.; Rief, M.; Schmidt, L.; Li, H.; Oesterhelt, F.; Gautel, M.; Gaub, H. E. Appl. Phys. A 1999, 68, 173-176.

(27) Fritz, J.; Baller, M. K.; Lang, H. P.; Rothuizen, H.; Vettiger, P.; Meyer, E.; Guntherodt, H. J.; Gerber, C.; Gimzewski, J. K. Science 2000, 288, 316-318.

(28) Clausen-Schaumann, H.; Seitz, M.; Krautbauer, R.; Gaub, H. E. Curr. Opin. Chem. Biol. 2000, 4, 524-530.

(29) Clausen-Schaumann, H.; Rief, M.; Tolksdorf, C.; Gaub, H. E. Biophys. J. 2000, 78, 1997-2007.

(30) Oesterhelt, F.; Oesterhelt, D.; Pfeiffer, M.; Engel, A.; Gaub, H. E.; Muller, D. J. Science 2000, 288, 143-146.

(31) Valle, M.; Valpuesta, J. M.; Carrascosa, J. L.; Tamayo, J.; Garcia,

R. J. Struct. Biol. 1996, 116, 390-398.

(32) Hansma, H. G.; Kim, K. J.; Laney, D. E.; Garcia, R. G.; Argman, M.; Allen, M. J.; Parsons, S. M. J. Struct. Biol. 1997, 119, 99-108. (33) Brandsch, R.; Bar, G.; Whangbo, M.-H. Langmuir 1997, 13, 63496353.

(34) Bar, G.; Rubin, S.; Parikh, A. N.; Swanson, B. I.; Zawodzinski, T. A.; Whangbo, M.-H. Langmuir 1997, 13, 373-377.

(35) Whangbo, M.-H.; Bar, G.; Brandsch, R. Appl. Phys. A 1998, 66 S1267-S1270.

(36) Patel, N.; Davies, M. C.; Heaton, R. J.; Roberts, C. J.; Tendler, S. J. B.; Williams, P. M. Appl. Phys. A 1998, 66, S569-S574.

(37) Noy, Z.; Sanders, C. H.; Vezenov, D. V.; Wong, S. S.; Lieber, C. M. Langmuir 1998, 14, 1508-1511.

(38) Friggeri, A.; Schönherr, H.; van Manen, H.-J.; Huisman, B.-H.; Vancso, G. J.; Huskens, J.; van Veggel, F. C. J. M.; Reinhoudt, D. N. Langmuir 2000, 16, 7757-7763.

(39) James, P. J.; Antognozzi, M.; Tamayo, J.; McMaster, T. J.; Newton, J. M.; Miles, M. J. Langmuir 2001, 17, 349-360.

(40) Sasahara, A.; Uetsuka, H.; Onishi, H. J. Phys. Chem. 2001, 105,
(41) Magonov, S. N.; Elings, V.; Whangbo, M.-H. Surf. Sci. 1997, 375 L385-L391.

(42) Magonov, S. N.; Elings, V.; Whangbo, M.-H. Surf. Sci. 1997, 389, $201-211$.

(43) Bar, G.; Thomann, Y.; Brandsch, R.; Cantow, H.-J.; Whangbo, M.H. Langmuir 1997, 13, 3807-3812.

(44) Bar, G.; Brandsch, R.; Whangbo, M.-H. Langmuir 1998, 14, $7343-$ 7347.

(45) Bar, G.; Ganter, M.; Brandsch, R.; Delineau, L. Langmuir 2000 , $16,5702-5711$

(46) Bar, G.; Delineau, L.; Häfele, A.; Whangbo, M.-H. Polymer 2001, 42, 3627-3632.

(47) Bar, G.; Brandsch, R.; Whangbo, M.-H. Surf. Sci. 1999, 422, L192L199.

(48) Burnham, N. A.; Behrend, O. P.; Oulevey, F.; Gremaud, G.; Gallo, P.-J.; Gourdon, D.; Dupas, E.; Kulik, A. J.; Pollock, H. M.; Briggs, G. A. D. Nanotechnology 1997, 8, 67-75.

(49) Tuite, E.; Lincoln, P.; Olofsson, J.; Becker, H.-C.; Önfelt, B.; Erts, D.; Nordén, B. J. Biomol. Struct. Dyn. 2000, Conversation 11 (2), $277-$ 283.

(50) Erts, D.; Polyakov, B.; Olin, H.; Tuite, E. Latv. J. Phys. Tech. Sci 2001, 4, 63-71.

(51) Liebermann, T. Ph.D. Thesis, Max-Planck-Institut für Polymerforschung, Mainz, Germany, 1998.

(52) Bloomfield, V. A., Crothers, D. M., Tinoco, I., Jr. Nucleic Acids Structures, Properties, and Functions; University Science Books: Herndon, VA, 2000

(53) Tinland, B.; Pluen, A.; Sturm, J.; Weill, G. Macromolecules 1997, $30,5763-5765$

(54) Aimé, J. P.; Michel, D.; Boisgard, R.; Nony, L. Phys. Rev. B 1999, $59,2407-2416$

(55) Tamayo, J.; Garcia, R. Langmuir 1996, 12, 4430-4435.

(56) Tamayo, J.; Garcia, R. Appl. Phys. Lett. 1997, 71, 2394-2396.

(57) Tamayo, J.; Garcia, R. Appl. Phys. Lett. 1998, 73, 2926-2928. 801

(59) Garcia, R.; Tamayo, J.; Paulo, A. S. Surf. Interface Anal. 1999 27, 312-316

(60) Marth, M.; Maier, D.; Honerkamp, J. J. Appl. Phys. 1999, 85, $7030-7036$

(61) Wang, L. Surf. Sci. 1999, 429, 178-185.

(62) Delineau, L.; Brandsch, R.; Bar, G.; Whangbo, M.-H. Surf. Sci. 2000, 448, L179-L187.

(63) Dubourg, F.; Aime, J. P. Surf. Sci. 2000, 466, 137-143.

(64) Paulo, A. S.; Garcia, R. Surf. Sci. 2001, 471, 71-79.

(65) Tortonese, M.; Kirk, M. Proc. SPIE-Int. Soc. Opt. Eng. 1997, 3009, $53-60$

(67) Joyce, S. A.; Thomas, R. C.; Houston, J. E.; Michalske, T. A.; Crooks, R. M. Phys. Rev. Lett. 1992, 68, 2790-2793. 